\title{
Retraction Note: On right congruences of semigroups having no proper essential right congruences, Semigroup Forum (2012) 85:369-380
}

\author{
Chong-yih Wu
}

Published online: 31 July 2013

(C) Springer Science+Business Media New York 2013

\section{Retraction to: Semigroup Forum (2012) 85:369-380 \\ DOI 10.1007/s00233-012-9423-1}

I withdraw my paper "On right congruences of semigroups having no proper essential congruences" which appeared in Semigroup Forum 85 (2012), 369-380.

This paper is a somewhat expanded version of a rough note by my late supervisor Robert H. Oehmke. He sent over that manuscript to me in 1999, suggesting that I join in by completing the results and then we would publish a paper jointly. Due to unforeseen circumstances, I could not complete the paper until much later, in 2009. Unfortunately, Professor Oehmke had passed away in 2003 before I had an opportunity to show him my completed research. After searching for relative keywords in Google and finding nothing of any significant relevance, I submitted the expanded paper to Semigroup Forum in 2009.

I was shocked to learn now that Professor Oehmke himself had published the results from his rough notes in a paper entitled "On the distributivity of the lattice of right congruences of a semigroup", Hadronic Journal 27 (2004), 458-472, submitted in 2003. Till now, I was unaware of this paper and of his decision, taken years after writing to me, to publish his own results based on the rough notes alone.

Clearly, a very large part of my paper coincides practically with large parts of Oehmke's paper. Had I known about Oehmke's paper, I would not have submitted mine, and therefore I withdraw my paper. I understand that I should have included a

The online version of the original article can be found under doi:10.1007/s00233-012-9423-1.

C.-y. Wu $(\varangle)$

Center of General Education, National Pingtung Institute of Commerce, Pingtung, Taiwan

e-mail: cwu@npic.edu.tw 
proper acknowledgement of the contribution from Robert H. Oehmke to my paper, giving him due credit for a large part of the results. I apologize that I did not do so. In addition, the main theorem in my paper contains errors that are not present in Professor Oehmke's original notes, for which mistake I also apologize. 